\title{
Trauma Surgery \& Acute Care Open \\ Advocacy efforts in trauma and acute care surgery: learning to walk
}

\author{
Lewis J Kaplan, ${ }^{1}$ Erik Barquist, ${ }^{2}$ Donald Jenkins, ${ }^{3}$ Orlando Kirton ${ }^{4}$
}

${ }^{1}$ Section of Trauma, Surgical Critical Care and Emergency Surgery, Perelman School of Medicine, Philadelphia, Pennsylvania, USA

${ }^{2}$ Department of Surgery, University of South Florida, Orlando, Florida, USA

${ }^{3}$ Department of Surgery, University of Texas Health Science, San Antonio, San Antonio, Texas, USA

${ }^{4}$ Department of Surgery, Abington-Jefferson Health, Abington, Pennsylvania, USA

\section{Correspondence to}

Dr Lewis J Kaplan, Perelman School of Medicine, Section of Trauma, Surgical Critical Care and Emergency Surgery

Penn-Presbyterian Medical Center, 1 MOB, Suite 120, Philadelphia, PA 19406, USA; lewis.kaplan@uphs.upenn.edu

Received 11 January 2017 Revised 24 February 2017 Accepted 27 February 2017

To cite: Kaplan $L J$ Barquist $E$, Jenkins $D$, et al. Trauma Surg Acute Care Open Published Online First: [please include Day Month Year] doi:10.1136/tsaco2017-000077
In modern American politics, advocacy is a focused and dynamically charged process. Despite the intense interplay in Washington, DC, advocacy efforts and activities remain more opaque for the majority of frontline healthcare providers. Advocacy efforts are not generally considered an essential element of daily practice. Instead, many providers may derive comfort from the belief that someone else will have the knowledge, desire, commitment, and time to speak and act on their behalf. Each of us are faced with challenges on a daily basis that relate to market, resource, access, or finance issues-all of which are reasonable advocacy targets. ${ }^{1}$ Limited engagement in advocacy by surgical care providers as a group is perhaps an indicator of disinterest, discomfort, or perhaps even apathy among members concerning advocacy and its impact on preserving current or garnering additional resources critical to our profession. While patient care activities must remain firmly planted at the pinnacle of our charge, one approach to consider is that advocacy efforts targeted at clearly defined aspects of care should be considered a professional activity, and given equal footing with administration, academic productivity, and teaching. ${ }^{2}$ While there may be knowledge deficits regarding advocacy, there appears to also be the concept that advocacy is 'someone else's' job.

It is important to learn from previous advocacy efforts that involved the trauma community. The Roundtable for Critical Care assembled a multiprofessional group of individuals and partnered them with a bipartisan, experienced advocacy team that led to actionable legislation and a critical care relevant bill put before Congress: the Critical Care Assessment and Improvement Act of 2014. This bill was in keeping with the Roundtable's tripartite focus of advanced care and ethics, innovation and outcomes, and disaster preparedness. This paradigm-partnering local and national expertise with professional advocacy experts-merits further exploration. One method of starting such relationships was the Roundtable's 'ICU At Home' program that pairs an intensive care unit (ICU) (or perhaps a trauma center) with their Representative and/or Senator to foster relationships and demonstrate relevant local needs.

The rapid evolution of acute care surgery (ACS) provides an example of specific advocacy on a national scale, carried to fruition at multiple local sites. A new brand was formed by creating a training pathway, credentialing metrics, tracking databases and element definitions. ${ }^{3}{ }^{4}$ Locally, acute care advocacy focused on enhancing emergency general surgery care, leveraging existing trauma and critical care relationships to craft pathways for emergency surgery patients, and rotations for ACS fellows on specialty services. ${ }^{3}$ This achievement demonstrates the necessity of engaging in local advocacy; however, there may be less surety when driving those efforts at the regional, state, or national level. Multiple reasons may underpin such discomfiture, including lack of knowledge, time, contacts, procedures, and uncertainty about the return on the time and capital investment in such a process, including general surgery resident perception of the value of the 'business of medicine'. ${ }^{6}$ Recognizing that each year often brings an increase in productivity targets, it is increasingly difficult to engage in advocacy efforts amidst the myriad of other responsibilities-a process not limited to general surgeons. ${ }^{7} 8$ The apparent comfort in being unengaged in advocacy work may be related to a sense of comfort that others will or should shoulder this activity set for them, perhaps being able to point to the success of the American Association for the Surgery of Trauma (AAST) at bringing ACS to fruition; this effort hinged on the dedicated work of a smaller subset of individuals on behalf of the entire organization. Despite the potential capacity of professional organizations to engage in advocacy, such efforts are often focused within a particular committee or committees on behalf of the membership rather than a more global membership-based approach. Even if interested in advocacy, many may be unsure how to proceed in becoming not only engaged but expert. As many members volunteer time to a host of organizations, the phenomenon of committee activity that benefits the entire organization is well entrenched. We submit that while such focused engagement is ideal for a single organization, it is not generally sufficient to effect national change. Accordingly, a more engaging advocacy target for surgeons in particular is to direct attention to the specific needs of the acute care community leveraging patient care priorities as the fulcrum on which a key agenda may pivot. We further conclude that one avenue to build momentum for interest in advocacy is to link to currently widely held anchors, such as a desire to perform scientific inquiry.

Currently, the advocacy needs of those pursuing academic research in trauma and injury are met through the efforts of the National Trauma Institute (NTI) and to a lesser, but important, extent through the activities of the American College of Surgeons Political Action Committee (ACS-PAC). Federal research funding is increasingly difficult to garner, in part due to the overall agency financial allocation, but also in part related to the plethora of worthy undertakings whose advocates clamor for specific project funding. ${ }^{9}$ By way of example, one needs look no further than pharmaceutical shortages, Zika virus 
therapy, and therapeutics for precision medicine. The NTI is an organization with a very specific focus on trauma care underpinned by funding trauma-related research. This highly focused effort has enjoyed success in driving research funds to over 30 investigators in 22 different states. There is no doubt that the Washington, DC, advocacy days hosted by the NTI have been successful, but further input from a larger number of trauma providers would be helpful. Additional focused efforts are found within CNTR (Coalition for National Trauma Research), an entity focused on establishing funding and an infrastructure for highquality trauma relevant new knowledge discovery. ${ }^{9-11}$ Since there are numerous domains that might benefit from advocacy efforts, a primary initiative would be to articulate the clearly focused needs and desires of relevant surgical societies and their members.

Models of such efforts abound and include the AustralianNew Zealand Intensive Care Society and the Canadian Critical Care Collaborative Trials Group, both of which have achieved prominence in scientific investigations as well as practice change. $^{12} 13$ Similarly, the Critical Care Societies Collaborative spans physician and nursing specialties and reaches outside the USA to the European Union through the European Society of Intensive Care Medicine with well described and specifically focused critical care research, position statements, and advocacy efforts. $^{14} 15$ One could envision, for example, multisociety efforts at crafting an Acute Care Collaborative with agenda items that would benefit from advocacy efforts toward a common goal addressing data, resources, and access for ACS. Indeed, such a group could focus national attention on relevant issues in aftercare for those who are transported from outlying regions to institutions at which our members practice; rehabilitation, convalescence, home care, and home infusion therapies are often less available in remote regions than those immediately surrounding the tertiary or quaternary care facilities in which the majority of members practice. Undoubtedly, such examples are but the proverbial tip of the iceberg of opportunity.

The results of the National Academies of Science, Engineering and Medicine report on 'Zero Preventable Deaths after Injury' is a prime example of the need to have surgeons as advocates, linking advances in military injury care with the potential for civilian lives saved if the same efforts were leveraged for civilian trauma care. ${ }^{16}$ This approach creates what has been termed a 'National Trauma Care System'. If this advocacy effort is going to be successful, it will be necessary for surgeons not only to be 'seated at the table' but for larger numbers of surgeons to speak to their elected national officials if our recommendations are to be realized. ${ }^{10}{ }^{16}$ That such advocacy-based success is realizable is underscored by the recent increase in Department of Defense funding addressing trauma care that established the Linking Investigations in Trauma and Emergency Services (LITES) Network, a system to capture and integrate data on prehospital care through convalescence. ${ }^{17}$

Since advocacy appears feasible and directly related to elements that impact daily clinical practice as well as scientific inquiry, one may view the need to engage in advocacy as an imperative. One may link this imperative to beneficence, justice, and autonomy, three of the classically described four Western ethical pillars of that also includes non-maleficence. ${ }^{18}$ Beneficence relates to the duty of care that medical professionals embrace, including acts of charity or kindness that are underpinned by a sense of doing good for others within the framework of a moral obligation. ${ }^{19}$ Advocating for both the profession, and in turn our patients, fits within this ethical imperative, and serves as a call to action. Advocacy also supports justice, a second pillar that relates to doing good for all in an equal fashion, across patient populations and medical centers alike in important domains such as access and care quality. Relatedly, as advocacy expands choices for patients and systems, it also supports autonomy. Thus, there are strong ethical imperatives supporting advocacy engagement for the surgeon.

Important next steps in this process as we move from crawling to learning to walk might be envisioned in the following fashion. First, surgical organizations may help by making advocacy efforts more mainstream within national meetings, instead of simply a campaign for funding. Second, specific training in advocacy methods could be offered alongside technique courses for surgical procedures. Third, and to some extent this is already being performed, professional journals should support publication of advocacy undertakings and their impact on healthcare. Fourth, there is no value assigned to advocacy efforts at academic medical centers that relate to time allocation or any aspect of reappointment or promotion in a codified way. National organizations may help recognize the value of these activities as part of one's professional activities and rescue them from being relegated to an individual effort undertaken on one's personal time. Finally, members need to embrace advocacy with the same vigor and dedication as they do patient care, education, and scientific inquiry.

Surgical organization corporate structures span the very small volunteer-led professional society to those that are led by a highly accomplished Chief Executive Officer and supported by professional staff. All embrace member volunteers in a myriad of society activities. Certainly, organizations with depth, clearly defined structure, and appropriate funding may engage in a more robust array of advocacy activities, including lobbyists, than those with small memberships and support structures. Nonetheless, not all advocacies require vast financial reserves, and a small professional organization runs the risk of equating a more diminutive treasury with a lack of capacity and capability to engage in advocacy. Successful advocacy may be supported with a time investment instead of a financial one; the aforementioned ICU At Home effort is one such example. Larger organizations, especially those with members of multiple specialties housed under a single umbrella structure may be challenged in defining an advocacy focus. A clearly defined focus is essential and is aided by securing member support for a specific advocacy agenda. Regardless of size, advocacy efforts are key in discharging the member ethical imperatives outlined above, and in supporting excellence in healthcare.

\section{CONCLUSION}

Advocacy efforts by surgical societies represent underdeveloped opportunities for improvement and engagement in sharp contradistinction to the already successful efforts at the discovery of new knowledge and the articulation of practice guidelines. As such, advocacy efforts may be considered frail by comparison to other better-developed and durable initiatives. It appears that advocacy interest often resides within a small group of members who might benefit from focused education and targeted opportunities to expand their foray into advocacy on behalf of critically ill and injured patients, and the societies to which they belong. Potential partnerships in advocacy efforts addressing issues common to professional organizations caring for ACS patients appears reasonable and offers the best potential to influence the national agenda.

Competing interests None declared.

Provenance and peer review Not commissioned; externally peer reviewed. 
Open Access This is an Open Access article distributed in accordance with the Creative Commons Attribution Non Commercial (CC BY-NC 4.0) license, which permits others to distribute, remix, adapt, build upon this work non-commercially, and license their derivative works on different terms, provided the original work is properly cited and the use is non-commercial. See: http://creativecommons.org/ licenses/by-nc/4.0/

\section{REFERENCES}

1 Morris JA, Fildes J, May AK, Diaz J, Britt LD, Meredith JW. American Association for the Surgery of Trauma's EGS Research Agenda Committee. A research agenda for emergency general surgery: health policy and basic science. J Trauma Acute Care Surg 2013;74:322-8

2 Tisherman SA, Kaplan LJ, Gracias VH, Beilman GJ, Toevs C, Byrnes MC, Coopersmith CM. Providing care for critically-ill surgical patients: challenges and recommendations. JAMA Surg 2013;148:669-74.

3 Duane TM, Dente CJ, Fildes JJ, Davis KA, Jurkovich GJ, Meredith JW, Britt LD. Defining the acute care surgery curriculum. J Trauma Acute Care Surg 2015;78:259-64.

4 Shafi S, Aboutanos MB, Agarwal SJr, Brown CV, Crandall M, Feliciano DV, Guillamondegui O, Haider A, Inaba K, Osler TM, Ross S. Emergency general surgery: definition and estimated burden of disease. J Trauma Acute Care Surg 2013;74:1092-7.

5 Tapia NM, Milewicz A, Whitney SE, Liang MK, Braxton CC. Identifying and eliminating deficiencies in the general surgery resident core competency curriculum. JAMA Surg 2014;149:514-18.

6 Meara JG, Greenberg SL. The Lancet Commission on Global Surgery Global surgery 2030: evidence and solutions for achieving health, welfare and economic development. Surgery 2015;157:834-5.

7 Sethi MK, Obremskey A, Sathiyakumar V, Gill JT, Mather RC III. The evolution of advocacy and orthopaedic surgery. Clin Orthop Relat Res 2013;471:1873-8.

8 Sarani B, Mayglothling J, Toevs C, Kaplan LJ. The burden of the US crisis in surgical critical care workforce and workflow. Am Surg 2015;81:19-22.

9 Smith SL, Price MA, Fabian TC, Jurkovich GJ, Pruitt BA Jr, Stewart RM, Jenkins DH. The National trauma research repository: ushering in a new era of trauma research (commentary). Shock 2016;46(3 Suppl):37-41.
10 Jenkins DH, Cioffi WG, Cocanour CS, Davis KA, Fabian TC, Jurkovich GJ, Rozycki GS, Scalea TM, Stassen NA, Stewart RM. Position Statement of the Coalition for National Trauma Research (CNTR) on The National Academies of Sciences, Engineering and Medicine (NASEM) Report, a national trauma care system: integrating military and civilian trauma systems to achieve zero preventable deaths after injury. J Trauma Acute Care Surg 2016;81:816-8.

11 Coalition for National Trauma Research. http://www.coalitionntr.org (accessed 4 Sep 2016).

12 Young P, Bailey M, Beasley R, Henderson S, Mackle D, McArthur C, McGuinness S, Mehrtens J, Myburgh J, Psirides A, Reddy S, Bellomo R, SPLIT Investigators, ANZICS CTG. Effect of a buffered crystalloid solution vs saline on acute kidney injury among patients in the intensive care unit: The SPLIT Randomized Clinical Trial. JAMA 2015:314:1701-10.

13 Finfer S, Chittock D, Li Y, Foster D, Dhingra V, Bellomo R, Cook D, Dodek P, Hebert $P$, Henderson W, et al., NICE-SUGAR Study Investigators for the Australian and New Zealand Intensive Care Society Clinical Trials Group and the Canadian Critical Care Trials Group. Intensive versus conventional glucose control in critically ill patients with traumatic brain injury: longterm follow-up of a subgroup of patients from the NICE-SUGAR study. Intensive Care Med 2015;41:1037-47.

14 Moss M, Good VS, Gozal D, Kleinpell R, Sessler CN. An Official Critical Care Societies Collaborative statement: burnout syndrome in critical care healthcare professionals: a call for action. Crit Care Med 2016;44: 1414-21.

15 Workforce. http://ccsconline.org/workforce (accessed 4 Sep 2016).

16 Berwick D, Downey A, Cornett E, eds. A National Trauma Care System: Integrating Military and Civilian Trauma Systems to Achieve Zero Preventable Deaths After Injury. Washington, DC: The National Academies Press, 2016.

17 Pitt to Lead Trauma Network, Up to $\$ 90 \mathrm{M}$ in Department of Defense-Funded Trauma Research, 2016. [online] Available at: http://www.upmc.com/media/ NewsReleases/2016/Pages/lites-dod.aspx (accessed 4 Jan 2017).

18 Beauchamp TL. The 'four principles' approach to health care ethics. Princ Health Care Ethics 2007:29:3-10.

19 Kinsinger FS. Beneficence and the professional's moral imperative. J Chiropr Humanit 2009;16:44-6. 